\title{
Pacific Abyssal Transport and Mixing: Through the Samoan Passage versus around the Manihiki Plateau
}

\author{
Larry J. Pratt, ${ }^{\mathrm{a}}$ Gunnar Voet, ${ }^{\mathrm{b}}$ Astrid Pacini, ${ }^{\mathrm{a}}$ Shuwen Tan, ${ }^{\mathrm{a}}$ Matthew H. Alford, \\ GlenN S. CARTER, ${ }^{\mathrm{c}}$ JAMES B. GiRTON, ${ }^{\mathrm{d}}$ AND Dimitris MENEMENLIS ${ }^{\mathrm{e}}$ \\ ${ }^{a}$ Department of Physical Oceanography, Woods Hole Oceanographic Institution, Woods Hole, Massachusetts \\ ${ }^{\mathrm{b}}$ Scripps Institute of Oceanography, La Jolla, California \\ ${ }^{\mathrm{c}}$ Department of Oceanography, University of Hawai'i at Mānoa, Honolulu, Hawaii \\ ${ }^{\mathrm{d}}$ Applied Physics Laboratory and School of Oceanography, University of Washington, Seattle, Washington \\ ${ }^{\mathrm{e}}$ Jet Propulsion Laboratory, California Institute of Technology, Pasadena, California
}

(Manuscript received 17 June 2018, in final form 6 April 2019)

\begin{abstract}
The main source feeding the abyssal circulation of the North Pacific is the deep, northward flow of 5-6 Sverdrups ( $\mathrm{Sv} ; 1 \mathrm{~Sv} \equiv 10^{6} \mathrm{~m}^{3} \mathrm{~s}^{-1}$ ) through the Samoan Passage. A recent field campaign has shown that this flow is hydraulically controlled and that it experiences hydraulic jumps accompanied by strong mixing and dissipation concentrated near several deep sills. By our estimates, the diapycnal density flux associated with this mixing is considerably larger than the diapycnal flux across a typical isopycnal surface extending over the abyssal North Pacific. According to historical hydrographic observations, a second source of abyssal water for the North Pacific is 2.3-2.8 Sv of the dense flow that is diverted around the Manihiki Plateau to the east, bypassing the Samoan Passage. This bypass flow is not confined to a channel and is therefore less likely to experience the strong mixing that is associated with hydraulic transitions. The partitioning of flux between the two branches of the deep flow could therefore be relevant to the distribution of Pacific abyssal mixing. To gain insight into the factors that control the partitioning between these two branches, we develop an abyssal and equator-proximal extension of the "island rule." Novel features include provisions for the presence of hydraulic jumps as well as identification of an appropriate integration circuit for an abyssal layer to the east of the island. Evaluation of the corresponding circulation integral leads to a prediction of 0.4-2.4 Sv of bypass flow. The circulation integral clearly identifies dissipation and frictional drag effects within the Samoan Passage as crucial elements in partitioning the flow.
\end{abstract}

\section{Introduction}

Bryden and Nurser (2003) have argued that turbulence in deep passages accounts for a significant portion of the total abyssal mixing in the Atlantic Ocean. Their estimates are based on the observed changes in density experienced when Antarctic Bottom Water (AABW) enters a deep passage and is locally mixed as a result of the instability, overturning, and turbulence that typically accompany strong hydraulic transitions. They trace the flow of AABW through several major passages, including the Vema Channel and Romanche Fracture Zone, estimate the turbulent buoyancy fluxes for each, and compare the sum to the total buoyancy flux required to close the abyssal mass budget. By their measure, mixing in the overflows tends to dominate mixing in the deep basins.

Corresponding author: Larry Pratt, lpratt@whoi.edu.
The abyssal Pacific was not included in the discussion by Bryden and Nurser (2003), perhaps because the corresponding deep passages are not as well observed as those in the Atlantic. However, it is well known that the North Pacific Ocean abyssal circulation is fed primarily by Antarctic-origin Bottom Water that has made its way northward from the Southern Ocean and passed through the Samoan Passage and nearby passages (Fig. 1) around $7^{\circ}-12^{\circ} \mathrm{S}$ (Reid and Lonsdale 1974). As a component of observations made along World Ocean Circulation Experiment (WOCE) line P31, Roemmich et al. (1996) and Rudnick (1997) deployed a line of current meters across the entrance of the Samoan Passage and calculated a 17-month average northward volume transport of $6.0 \mathrm{~Sv}$ $\left(1 \mathrm{~Sv} \equiv 10^{6} \mathrm{~m}^{3} \mathrm{~s}^{-1}\right)$. This value can be compared with hydrographic estimates of $6.0 \mathrm{~Sv}$ by Taft et al. (1991) based on the Transport of Equatorial Waters (TEW) expedition, and with Freeland's (2001) value of $8.4 \mathrm{~Sv}$ 


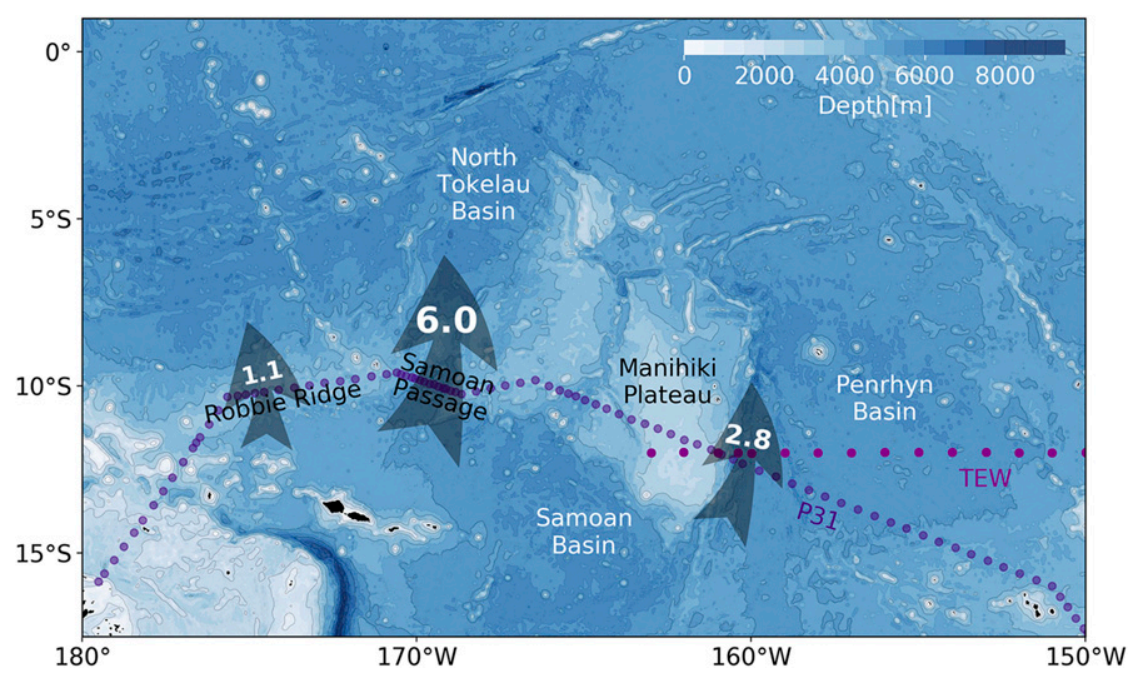

FIG. 1. The local bathymetry of the Samoan Passage, Manihiki Plateau, and Penrhyn basin. The arrows show volume flux estimates due to Roemmich et al. (1996) and based on WOCE line P31 (blue dots). The transport across Robbie Ridge and that to the east of the Manihiki Plateau are hydrographic-based, geostrophic estimates, whereas the 6.0-Sv transport in the Samoan Passage is based on moored current meters (Rudnick 1997). Voet et al. (2016) measure a 15-month mean Samoan Passage transport of $5.4 \mathrm{~Sv}$ based on current meters moored in roughly the same location. A second northward transport estimate of $2.3 \mathrm{~Sv}$ to the east of the Manihiki Plateau was made by Roemmich et al. (1996) based on data collected by Taft et al. (1991) along the more sparsely spaced TEW stations (maroon dots).

based on WOCE line P31N data. Freeland (2001) and Whitehead (2005) also made estimates (5.7 and 7.1 Sv, respectively) using hydraulic control formulas. A recent field campaign (Alford et al. 2013; Voet et al. 2015, 2016) included a 15-month record from moored current meters across the entrance, resulting in a volume transport estimate of 5.4 Sv (Voet et al. 2016). In summary, hydrographic and hydraulic flux estimates lie reasonably close to the time-average estimates of $6.0 \mathrm{~Sv}$ (Roemmich et al. 1996) and 5.4 Sv (Voet et al. 2016) made from direct current meter measurements. It is notable that fluctuations in the instantaneous volume transport ranging from 1-2 to over $10 \mathrm{~Sv}$, much of it due to tidal variability, were observed in the two current meter deployments (Roemmich et al. 1996; Rudnick 1997; Voet et al. 2016).

There is also evidence that a significant portion of the total northward volume transport bypasses the Samoan Passage and flows around the east side of the Manihiki Plateau (Fig. 1). Based on the hydrographic data collected as part of WOCE Section P31 (Talley 2007), Roemmich et al. (1996) noted that the isopycnals in the Penrhyn basin slope up in the westward direction along the eastern flank of the Manihiki Plateau, suggesting the presence of a deep western boundary current. They estimated a northward transport of $2.8 \mathrm{~Sv}$. Previous to this estimate, Taft et al. (1991) had examined hydrographic data in the western portion of the Penrhyn basin, collected as part of the TEW cruise. They did not present a transport estimate, noting only that the water properties lack evidence of a high-latitude source. However, Roemmich et al. (1996) reexamined the TEW data and calculated a northward transport of $2.3 \mathrm{~Sv}$. (They also noted that the section spacing was larger than for the P31 data.) The time dependence present in the Samoan Passage may also be present in any bypass flow, so that a calculation based on a single hydrographic section may depend on when the section was taken.

Alford et al. (2013) show that the Samoan Passage contains a complex of sills and passages, with hydraulically controlled overflows, overturns, hydraulic jumps, and highly elevated levels of energy dissipation. Their observations suggest that AABW with potential temperature less than $0.7^{\circ} \mathrm{C}$ is mixed away. In addition, the primary signature of North Atlantic Deep Water, a local salinity maximum above the bottom layer of Antarctic Bottom Water (Reid and Lynn 1971), is also mixed away within the passage. Little is known about mixing to the east of the Manihiki Plateau, but the steeply sloping isotherms along the eastern boundary of the plateau in WOCE Section P31 (Fig. 3) suggest that the width $(\cong 300 \mathrm{~km})$ of the deep western boundary current is significantly larger than the typical width $(<50 \mathrm{~km})$ of the individual channels that contain the deep transport in the Samoan Passage. This and the lack of constraining channel walls suggest that the branch of the northward 
flow lying to the east of the Manihiki Plateau is broader and slower, and therefore less prone to the intense vertical mixing that can occur when a stratified fluid spills over a sill. It is certainly possible for hydraulic transitions to occur within geostrophic boundary currents, especially where capes, headlands, and offshore ridges are present (e.g., Dale and Barth 2001) and there are several ridges that protrude from the northeast corner of the Manihiki Plateau (Fig. 1). However, evidence from a numerical simulation, described later in this manuscript, suggests that the near bottom flow is steered around, and not over them. Mixing due to water spilling over these ridges, either directly or driven by tides (as in Musgrave et al. 2016) would tend to be weakened by the topographic steering.

Other evidence for mixing and transport east of the Manihiki Plateau appears to be inconclusive. There are no known abyssal microstructure measurements in the Penrhyn basin. WOCE Section P31 does not reveal the presence of a salinity maximum corresponding to NADW, either within the Samoan Passage or to the east of the Manihiki Plateau. Reid and Lonsdale (1974) report on three CTD casts taken east of the Manihiki Plateau as part of the Styx Expedition. Some current meter measurements were made just above the bottom. No measurements revealed bottom potential temperatures colder than $0.82^{\circ} \mathrm{C}$, leading the authors to comment on the apparent lack of northward transport in the western Penrhyn basin. However, the near bottom velocity at one of the locations was less than $1 \mathrm{~cm} \mathrm{~s}^{-1}$ and was not measured at the other two locations, so it is not clear that any of the stations were positioned in the path of the deep western boundary current.

The mixing that occurs along the east Manihiki branch of the northward flow is likely to be quite different, and perhaps of lower intensity, than what is experienced in the Samoan Passage. Fluid parcels in the east branch may also experience longer transit times and distances compared with parcels that pass directly through the Samoan Passage. For this reason it is relevant to understand the factors that determine the division of volume flux between this branch and the hydraulically controlled Samoan Passage branch. Apart from mixing, it is of general interest to understand why abyssal flows follow certain pathways when multiple choices are possible. We will attempt to gain insight into these questions by examining vorticity and circulation balances as expressed in an extension of the "island rule" (Godfrey 1989) to an abyssal layer. The purpose is to predict the northward transport to the east of the Manihiki Plateau and, more importantly, identify the key factors that set the volume transport.
This is not the first application of circulation integrals in pursuit of a better understanding of deep circulation (e.g., Pedlosky et al. 2011). However, the presence in the Samoan Passage of hydraulic processes, with enhanced mixing and bottom drag, along with the proximity of the equator, force us to contend with some novel and interesting features. We will detail these in section 2 and then apply the result to Samoan Passage/Manihiki geography (section 3), drawing upon data described in Alford et al. (2013) and Voet et al. (2015, 2016). Section 4 will revisit the topic of abyssal mixing in light of the foregoing results. We will argue that the Samoan Passage plays a dominant role in the abyssal buoyancy flux budget for the North Pacific and we will offer some thoughts on how the existence of the Manihiki bypass flow enters this narrative, and why it might be important in a warming abyss.

\section{Island rule formulation}

\section{a. 1.5-layer approximation and dynamics}

For simplicity and tractability, we will assume that the bulk of the deep-water flow can be modeled as a single, homogeneous layer that is overlain by an inactive region with slightly lower density. There are a number of reasonable choices for the interface, but observations reported in Voet et al. (2015, their Fig. 4) strongly suggest the $1^{\circ} \mathrm{C}$ potential temperature surface as the best overall choice. In particular, velocity profiles from a lowered ADCP show that the velocity diminishes rapidly to zero as one passes upward across the $1^{\circ} \mathrm{C}$ surface. The thickness of the underlying, active layer is denoted by $d(x, y, t)$, the corresponding reduced gravity by $g^{\prime}$, and the motion of the layer is governed by the shallow water equations with the Coriolis parameter $f(y)$. (Calculation of the numerical value of $g^{\prime}$ in such a model is often problematic, but our particular formulation of the problem will not require a numerical value.) We begin by considering a domain with simplified geometry (Fig. 2), bounded to the west by a straight wall and with a rectangular island or plateau. Far to the east the layer depth vanishes along a grounding contour. The strait that separates the western boundary and plateau contains at least one sill with an overflow and an energy dissipating hydraulic jump (red patch).

A generalized version of Godfrey's (1989) rule can be formulated by first writing the shallow-water momentum equation in the convenient form

$$
\frac{\partial \mathbf{u}}{\partial t}+(\zeta+f) \mathbf{k} \times \mathbf{u}=-\nabla B+\mathbf{D},
$$




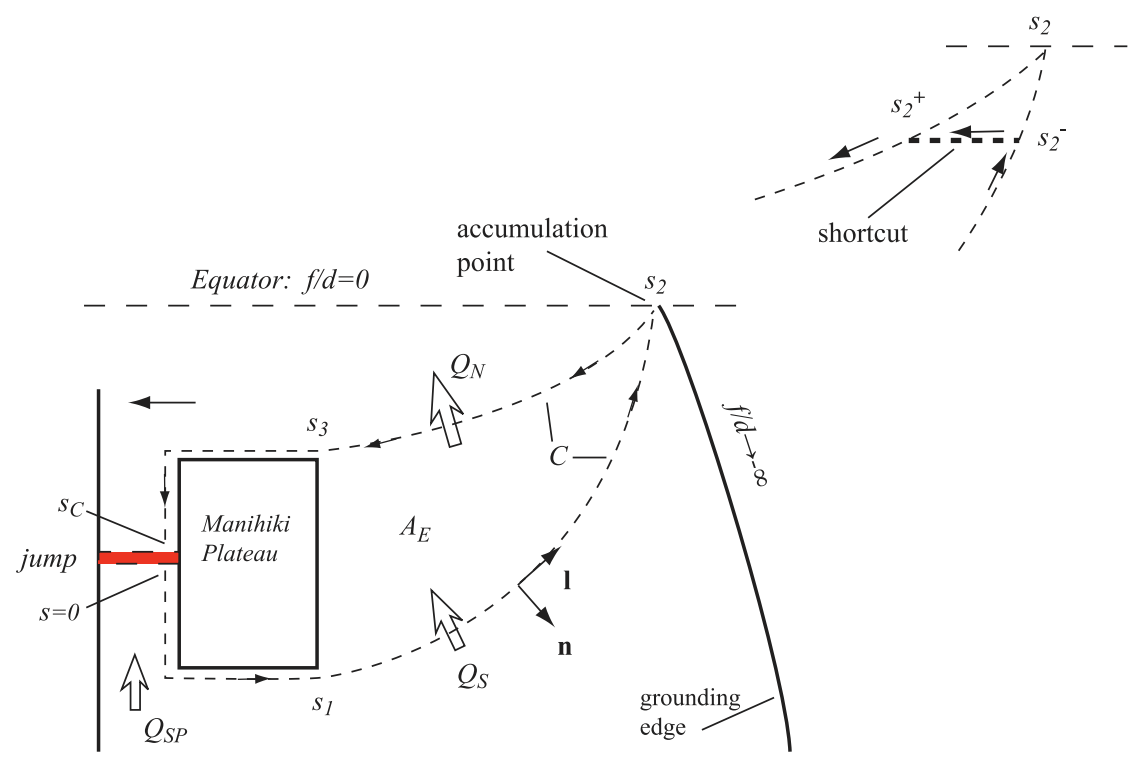

FIG. 2. Idealized setup for the formulation of the island rule to predict the volume transport $Q_{S}$ to the east of the Manihiki Plateau. The inset shows the (dashed) shortcut introduced to avoid the equator.

where $\mathbf{u}=(u, v)$ is the horizontal velocity, $f$ is the Coriolis parameter, $\zeta$ is the vertical component of relative vorticity, $B=|\mathbf{u}|^{2} / 2+g^{\prime}(d+h)$ is the Bernoulli function, $h$ is the bottom elevation, and $\mathbf{D}$ represents bottom frictional drag. This equation holds everywhere except within the hydraulic jump, where turbulent and nonhydrostatic effects prevail.

We now integrate the tangential component of (1) about a fixed, nearly closed circuit $C$ that begins just upstream of the jump (at the point $s=0$ in Fig. 2) and ends just downstream of the jump $\left(s=s_{C}\right)$. The contour runs along three sides of the plateau, assumed to be vertical walls and therefore admitting no cross-flow. The path of the contour to the east of the plateau will be explained shortly. The result of the integration is

$\frac{\partial}{\partial t} \int_{0}^{s_{C}} \mathbf{u} \cdot \mathbf{l} d s+\int_{0}^{s_{C}}(f+\zeta) \mathbf{u} \cdot \mathbf{n} d s=\delta B+\int_{0}^{s_{C}} \mathbf{D} \cdot \mathbf{l} d s$,

where $\mathbf{I}$ and $\mathbf{n}$ are unit vectors orientated tangent and normal to the contour (Fig. 2) and

$$
\delta B=\left.B\right|_{s=0}-\left.B\right|_{s=s_{C}}
$$

is the (positive) drop in the energy (Bernoulli function) across the jump.

The inclusion of the term $\delta B$ in (2) represents an important departure from other forms of the island rule, where the integration contour $C$ is closed and the contribution from the derivative of the Bernoulli function is nil after integration around $C$. The danger in using this approach here is illustrated by considering a hydraulic jump in a single-layer, homogeneous flow with a free surface and no bottom drag. The jump is very abrupt and occurs over a downstream distance on the order of the fluid depth. As pointed out by Pratt and Whitehead (2008, section 1.6b) integration of (1) from a point slightly upstream to a point slightly downstream of the jump would lead to the conclusion that $\delta B=0$, whereas it is well known that the jump contains a high level of internal dissipation. The pitfall comes from integration of an equation across a zone in which the equation does not apply, and it is for this reason that we avoid carrying the integration through the jump. A desirable advance would be a parameterization of $\delta B$ in terms of upstream conditions, something that is possible in the homogeneous case. Thorpe (2010) and Thorpe and Li (2014) have made progress on this problem in connection with jumps in stratified fluids, and Thorpe et al. (2018) have shown that the results apply to a particular segment of the Samoan Passage flow where strong overturns are observed. However, strong dissipation, overturns, and mixing occur in other parts of the Samoan Passage and it is not clear how to parameterize all of these. We will instead rely on direct measurements of dissipation to evaluate $\delta B$.

The second term in (2) is nonzero only over the portions of the contour that do not follow a boundary. Consider this integral over the segment $s_{1}<s<s_{2}$. Following Pedlosky et al. (1997) it is advantageous to choose this segment to coincide with a contour of constant potential vorticity, in which case 


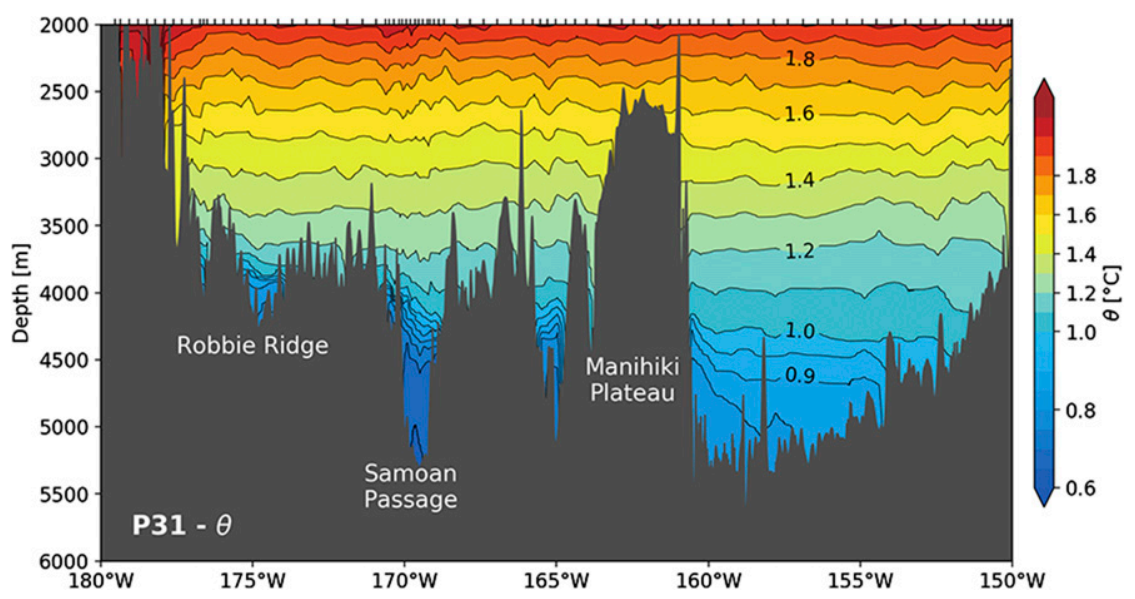

FIG. 3. WOCE Section P31 of potential temperature across the Samoan Passage and the Manihiki Plateau. The location of the P31 line is indicated in Fig. 1. Note that the gap at $165^{\circ} \mathrm{W}$ is topographically blocked farther to the north. Our hypothetical lower layer consists of water colder than $1^{\circ} \mathrm{C}$. Constructed from data available on the World Ocean Atlas.

$\int_{s_{1}}^{s_{2}}(\zeta+f) \mathbf{u} \cdot \mathbf{n} d s=\int_{s_{1}}^{s_{2}} \frac{(\zeta+f)}{d} d \mathbf{u} \cdot \mathbf{n} d s=q_{S} \int_{s_{1}}^{s_{2}} d \mathbf{u} \cdot \mathbf{n} d s$

where $q_{S}=(f+\zeta) / d$ is the potential vorticity and $Q_{S}=\int_{s_{1}}^{s_{2}} d \mathbf{u} \cdot \mathbf{n} d s$ is the volume flux across this segment.

\section{b. The integration contour}

Let us now consider how the shape of the contour $s_{1}<s<s_{2}$ is determined. Since the flow is deep and is expected to have low Rossby number, we will assume that $q_{S}$ is dominated by the contribution from $f / d$. To visualize the layer thickness $(d)$ field, consider WOCE Section P31 (Fig. 3), which extends roughly east to west, and cuts across the Penrhyn basin and Samoan Passage. The $\theta=1.0^{\circ} \mathrm{C}$ surface lies at about $4000-\mathrm{m}$ depth in the Samoan Passage (near $170^{\circ} \mathrm{W}$ ) and extends across the Penrhyn basin to the east of the Manihiki Plateau, grounding at the eastern slope near $152^{\circ} \mathrm{W}$. This grounding location marks the edge $(d=0)$ of the lower layer and is indicated by a solid line at the eastern edge in Fig. 2. The regional location of the grounding line can be seen in a plot of the depth of the $1^{\circ} \mathrm{C}$ surface (Fig. 4). Water colder than $1^{\circ} \mathrm{C}$, which corresponds to our model

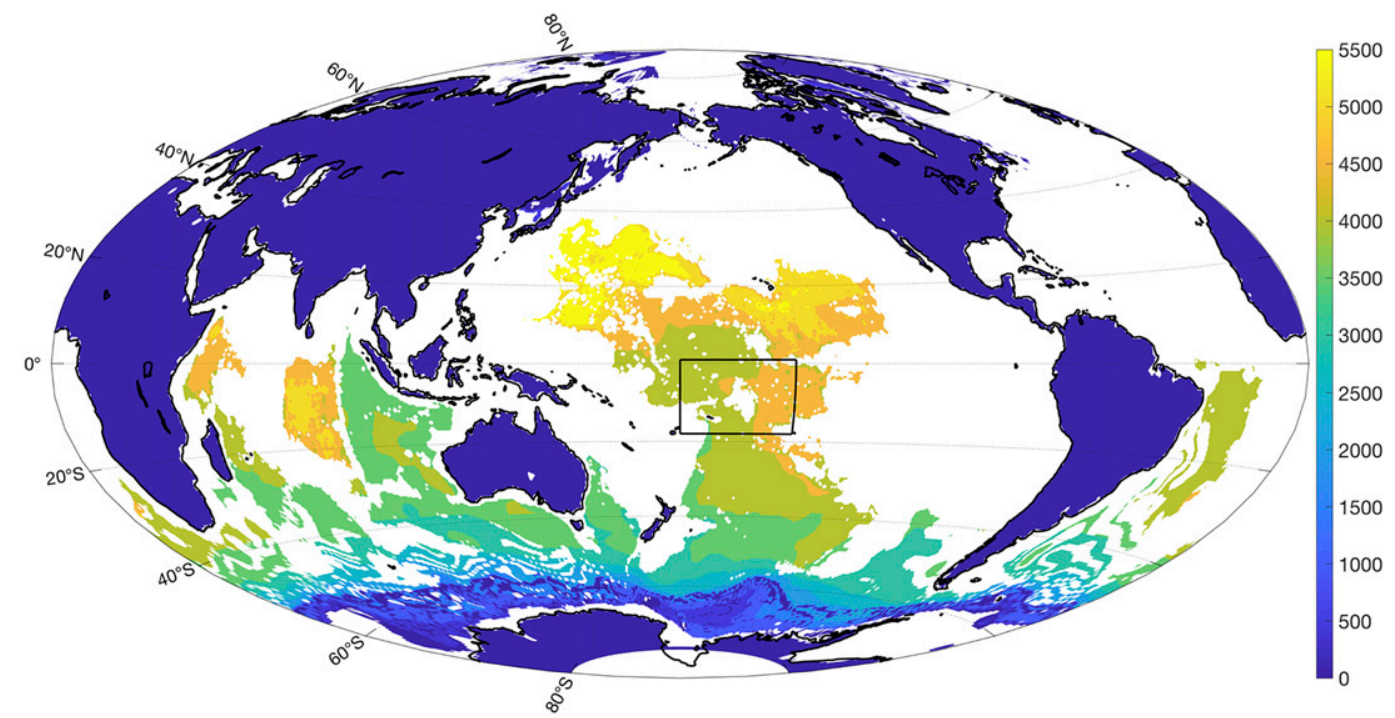

FIG. 4. Depth of $1^{\circ} \mathrm{C}$ potential temperature surface in the Pacific. The colored area north of the equator is used to estimate the average diapycnal velocity across the $1^{\circ} \mathrm{C}$ surface. The rectangle indicates the area shown in Fig. 1. (Made from World Ocean Atlas data.) 


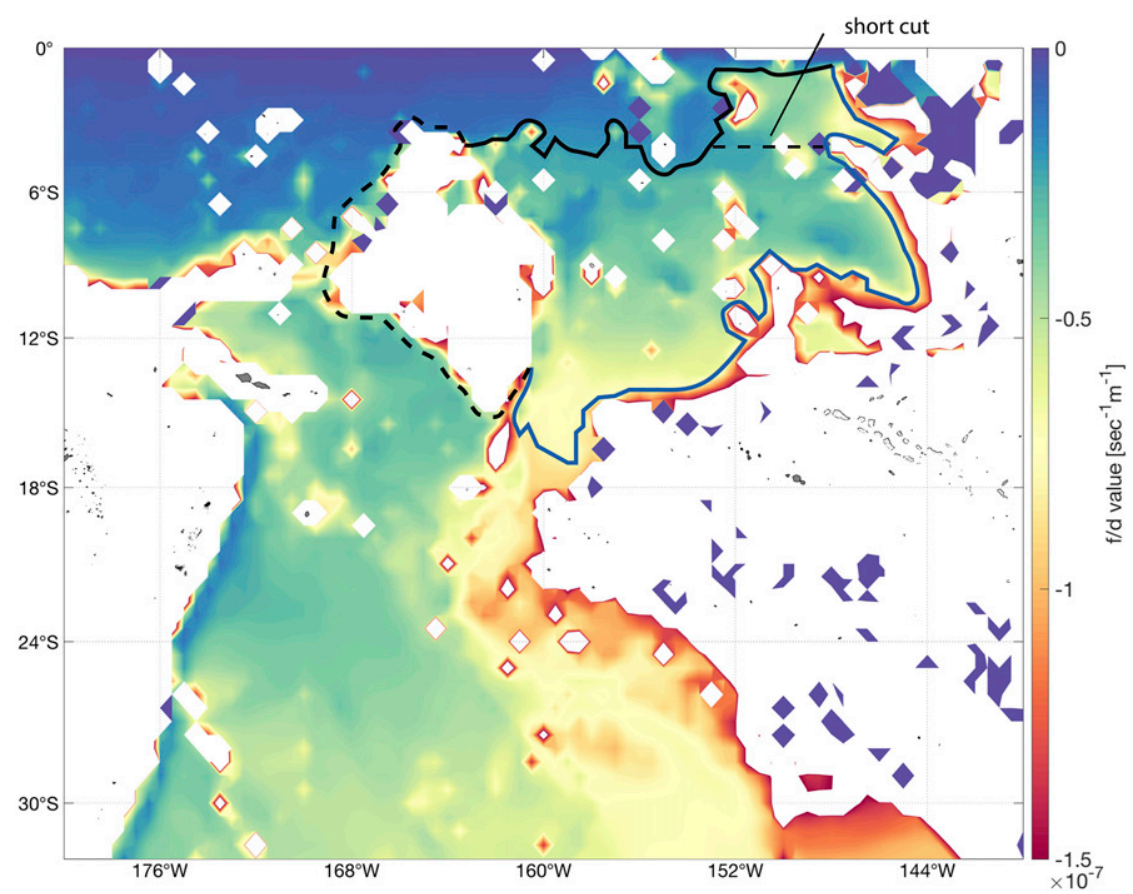

FIG. 5. One choice for the integration contour $C$ as represented by the thick blue, black, and dashed black curves. The solid blue and black portions represent the southern and northern segments of the portion of $C$ to the east of the Manihiki Plateau and correspond to different values of constant $f / d$. The short dashed zonal segment is the shortcut at $4.0^{\circ} \mathrm{S}$. The dashed contour to the east of the Manihiki Plateau completes the circuit. The colors indicate $f / d$ for the layer below $1^{\circ} \mathrm{C}$. Thin black and red curves show other contours of constant $f / d$ with values corresponding to those for the northern and southern segments of $C$. These often occur where bumps in the topography create small closed contours of constant $f / d$. White areas indicate regions where the bottom temperature is warmer than $1^{\circ} \mathrm{C}$.

layer, forms a cold tongue that extends northward from the Southern Ocean, through the Samoan Passage and around the east side of the Manihiki plateau, crossing the equator and terminating in the tropical North Pacific. The grounding contour corresponds to the eastern edge of this tongue, also shown in a magnified view in Fig. 5.

Next consider a contour of constant $f / d$ that begins at the southeast corner $\left(s=s_{1}\right)$ of the plateau in Fig. 2. As one moves eastward, away from this corner, $d$ decreases and thus one must move toward the equator in order to maintain a constant value of $f / d$, which for our Southern Hemisphere example is negative. Note also that $f / d$ tends to $-\infty$ at the grounding edge of the domain to the east, and approaches zero at the equator, so the intersection of the equator and the grounding contour is a singular point for the $f / d$ field. Since all values in the range $-\infty<f / d<0$ occur in its near neighborhood, the intersection acts as an accumulation point for fld contours with negative values. If this is true as well for the constant $f / d$ segment that begins at the northeast corner $\left(s=s_{3}\right)$ of the plateau, then the contours will meet at the accumulation point and the combined segments forming the portion of $C$ to the east of the island will look something like the horn-shaped contour $\left(s_{1}, s_{2}, s_{3}\right)$ in Fig. 2.

\section{c. Remarks on the singularity in the f/d field}

The apparent singularity at the equator only exists to the extent that the approximation $|f| \gg|\zeta|$ is carried all the way to the equator. The actual shape of a constant potential vorticity contour near the equator is influenced by the relative vorticity field there and the two contours emanating from the corners of the island will generally not meet. Although it might be possible to invoke a theory for the structure of the flow near the equator (e.g., Pedlosky 1987), none contemplate the special condition of our abyssal flow, including the grounding of the edge of our layer there. We can, however, estimate the error incurred through the neglect of relative vorticity by excising the unknown portion of the contour and replacing it by a "shortcut," as shown in the inset of Fig. 2. The shortcut is chosen to be zonal so that any cross-contour advection of potential 
vorticity due to currents parallel to the equator is zero. Ideally, the zonal segment is short and sufficiently far from the equator that $f$ dominates the absolute vorticity. The procedure for estimating the error incurred as a result of altering the contour is presented in appendix A and found to be insignificant for the Manihiki application.

It should be noted that the apparent equatorial singularity is a feature that is avoided in most other layerbased island rule formulations by imposition of vertical walls at eastern boundaries. For example, the zonal sections of $C$ in Godfrey's (1989) original work terminate at the South American coast. Had Godfrey chosen to confront the topographic effects of the continental slope and shelf, he might have allowed his southern contour to bend equatorward in order to maintain constant $f / d$, similar to what we have done. This southern contour would have then met the northern segment of the contour (already located close to the equator). This alteration in the integration path would have affected only a small portion of the total length, so the transport prediction would likely not have changed much.

Although the singularity in the $f / d$ field is in some sense removable, it functions as an important organizing feature for the integration contour west of the plateau. The two constant $f / d$ segments originating at the northern and southern tips of the plateau are attracted by the singularity and are therefore drawn close to each other as the equator is approached, allowing one to form a closed contour by introducing the shortcut segment. Even if we knew the relative vorticity field and could thereby trace the contours right to the equator, we would still need to join them somehow.

\section{d. The integral constraint}

We now continue with the formulation that neglects relative vorticity near the equator, and will quote the estimated error when predictions of the transport are given. The second integral in (2) can, in view of (3), be approximated as

$$
\begin{aligned}
q_{S} \int_{s_{1}}^{s_{2}} d \mathbf{u} \cdot \mathbf{n} d s+q_{N} \int_{s_{2}}^{s_{3}} d \mathbf{u} \cdot \mathbf{n} d s & =q_{N} Q_{N}-q_{S} Q_{S} \\
& \cong\left(\frac{f}{d}\right)_{N} Q_{N}-\left(\frac{f}{d}\right)_{S} Q_{S} .
\end{aligned}
$$

Here $Q_{s}$ is the volume flux crossing the southern segment, and we use the convention that this flux is positive if it moves fluid into the enclosed area $A_{E}$ lying within $C$ and to the east of the island (Fig. 2). Parameter $Q_{N}$ is the volume flux crossing the northern segment and is regarded as positive if it moves fluid out of $A_{E}$. If the flow is steady, the difference $\delta Q=Q_{s}-Q_{N}$ is the total upward diapycnal volume flux crossing the $1^{\circ} \mathrm{C}$ surface over the area $A_{E}$.

We can rewrite the right-hand side of (4) as

$$
\begin{aligned}
& (f / d)_{N}\left(Q_{S}-\delta Q\right)-(f / D)_{S} Q_{S} \\
& \quad=\left[(f / d)_{N}-(f / d)_{S}\right] Q_{S}-(f / d)_{N} \delta Q
\end{aligned}
$$

where

$$
\delta Q=\iint_{A_{E}} w_{e} d A
$$

and where $w_{e}(x, y, t)$ is the diapycnal velocity normal to the bounding interface, in our case the $1^{\circ} \mathrm{C}$ surface. Equation (2) now becomes

$$
\begin{aligned}
{\left[(f / d)_{N}-(f / d)_{S}\right] Q_{S}=} & (f / d)_{N} \iint_{A_{E}} w_{e} d A+\delta B \\
& +\int_{0}^{s_{C}} \mathbf{D} \cdot \mathbf{l} d s-\frac{\partial}{\partial t} \int_{0}^{s_{C}} \mathbf{u} \cdot \mathbf{l} d s .
\end{aligned}
$$

Note that the presence of a hydraulic jump (resulting in a positive drop $\delta B$ in the Bernoulli function) acts to increase $Q_{s}$. Also note that if $w_{e}>0$, (5) predicts a negative (southward) transport $Q_{S}$ provided that the second, third and fourth terms on the right-hand side are neglected, a situation directly analogous to the traditional island rule. In this case, a positive $\delta B$ or drag $\mathbf{D} \cdot \mathbf{I}$ is necessary in order to produce northward $Q_{S}$. The significance of the sign of $\delta B$ can be motivated through consideration of a moving column of fluid with $B=$ $\left(u^{2}+v^{2}\right) / 2+g^{\prime} d+g^{\prime} h$. If the flow is steady and the column moves along a streamline that terminates in a stagnation point, then the elevation $d+h$ at that point is given by $B / g^{\prime}$. The term $\delta B / g^{\prime}$ is thus the potential elevation drop, equivalent to a pressure drop, across a hydraulic jump based on loss of energy within the jump. When $B$ experiences a net drop between two ends ( $s=0$ and $s=s_{C}$ ) of $C$, this drop acts as a net stress along the contour. In the case of the Manihiki Plateau/Samoan Passage system, this stress acts in an anticlockwise direction, whereas clockwise circulation is generated by vortex stretching due to upwelling over $A_{E}$ and by the convergence of planetary vorticity due to northward flow across the open parts of $C$. Thus a positive $\delta B$ and/or positive bottom drag $\mathbf{D} \cdot \mathbf{I}$ is necessary if one is to obtain a steady, balanced northward flow.

It is possible, of course, that the average value of $w_{e}$ over $A_{E}$ is $<0$. As pointed out by Ferrari et al. (2016), downwelling can occur over a segment of the abyssal water column where the turbulent buoyancy flux increases toward the bottom. Measurements by microstructure 
profilers in the abyssal Penrhyn basin could inform this issue, but we know of no such measurements.

\section{Application to Manihiki Plateau}

We now attempt to predict the time-mean flow rate to the east of Manihiki. In doing so, we will assume that the final term in (5) is negligible in a long-term time mean. Then (5) can be rearranged as

$$
Q_{S}=\frac{(f / d)_{N} \iint_{A_{E}} w_{e} d A_{E}+\delta B-\int_{0}^{s_{C}} C_{d} \frac{|\mathbf{u}|}{d} \mathbf{u} \cdot \mathbf{l} d s}{\left[(f / d)_{N}-(f / d)_{S}\right]} .
$$

A quadratic drag term with dimensionless drag coefficient $C_{d}$ has been used to represent the frictional bottom drag. Pratt and Pedlosky (1998) also considered frictional drag in a strait to the west of an island, but the flow was barotropic and wind driven, the drag linear, and hydraulic jumps and other transitions were not in play. One might ask why topographic form drag does not appear in formulation; it is, in fact, avoided by the particular form (1) of the momentum equation. Had we started with the depth-integrated version of the momentum equation, form drag would explicitly arise. Finally, it is noted that the reduced gravity coefficient $g^{\prime}$ arises only within the term $\delta B$. Since the latter will be estimated from direct measurements of dissipation, the numerical value of $g^{\prime}$ is not required.

\section{a. Integration contour}

For the traditional island rule, an important consideration in choosing the integration contour $C$ is avoidance of the eastern boundary of the island. This boundary may support a western boundary layer, and the corresponding high levels of friction will contribute to the circulation integral in ways that are significant and difficult to estimate. This is why Godfrey (1989) chose to route $C$ around the western side of the island, which cannot support a western boundary layer. This motivation is less relevant in the present case, since friction and dissipation are potentially significant on both the east and west sides of the Manihiki Plateau. In our case the choice is dictated by the fact that the dissipation and velocity have been directly measured along the west side, within the Samoan Passage.

Another consideration that figures in the selection of $C$ is that the thickness of our hypothetical layer (all water colder than $1^{\circ} \mathrm{C}$ ) vanishes around the edge of the Manihiki Plateau. In textbook examples of the island rule, the plateau would have vertical sidewalls, and one would choose that portion of $C$ that wraps around the western side of the plateau to lie along the vertical walls, this in order to avoid horizontal flow across $C$ there. In the present case, the same outcome could be accomplished, in principle, by locating the western portion of $C$ to coincide with the contour along which the $1^{\circ} \mathrm{C}$ surface grounds, precluding flow across $C$ there. However, the quadratic drag term in our momentum equation, which contains a factor of $1 / d$, would then be difficult to estimate. As a compromise, we locate $C$ slightly outside of the grounding contour, where that $d$ is nonzero.

With these considerations in mind, we have mapped out a range of reasonable integration contours, each pinned to different 'corners' of the Manihiki Plateau. One such contour appears in Fig. 5.

\section{b. Diapycnal upwelling across the interface}

The first term in the numerator on the right-hand side of (6) is the area integral of the diapycnal velocity across the $1^{\circ} \mathrm{C}$ surface. This is the analog to the wind stress term in the traditional island rule, equivalent to the integral of the wind stress curl over an area. One means of estimating the diapycnal velocity would be to assume a onedimensional balance in the buoyancy equation with a turbulent diffusivity inferred from microstructure measurements. However, we have not been able to identify any microstructure observations in the region east of Manihiki and within the Penrhyn basin. Instead we estimate a diapycnal velocity for the $1^{\circ} \mathrm{C}$ surface as a whole north of the equator by dividing its surface area (Fig. 4) by the $9.9 \mathrm{~Sv}$ of total transport estimated by Roemmich et al. (1996) as approaching the equator from the south. This yields a value $w_{e}=4.4 \times 10^{-5} \mathrm{~cm} \mathrm{~s}^{-1}$, which, when integrated over the wetted area enclosed by the contour shown in Fig. 5, yields $0.87 \mathrm{~Sv}$. Other reasonable choices for the contour give values up to $0.99 \mathrm{~Sv}$. The corresponding term in (6) gives contributions in the range from -0.14 to $-0.24 \mathrm{~Sv}$ toward $Q_{N}$. The above value of $w_{e}$ is an order of magnitude greater than the average value of deduced from microstructure and fine structures measurements within $10^{\circ}$ of the equator (see Kunze et al. 2006). We therefore treat our value as an upper bound, with a lower bound of zero, noting that the Penrhyn basin has relatively smooth topography and may therefore have an average $w_{e}$ that is less than the average value of the area covered by the $1^{\circ} \mathrm{C}$ isotherm north of $10^{\circ} \mathrm{S}$. A final caveat is that, as discussed above, there could be net downwelling over the Penrhyn basin, but there is nothing that would permit us to quantify this.

This weak southward flow is consistent with the idea that an upward diapycnal velocity across the $1^{\circ} \mathrm{C}$ interface leads to vortex stretching in the fluid below, and that in the absence of relative vorticity this must cause fluid move southward to preserve potential vorticity, the same idea that underlies the Stommel and Arons (1960) 


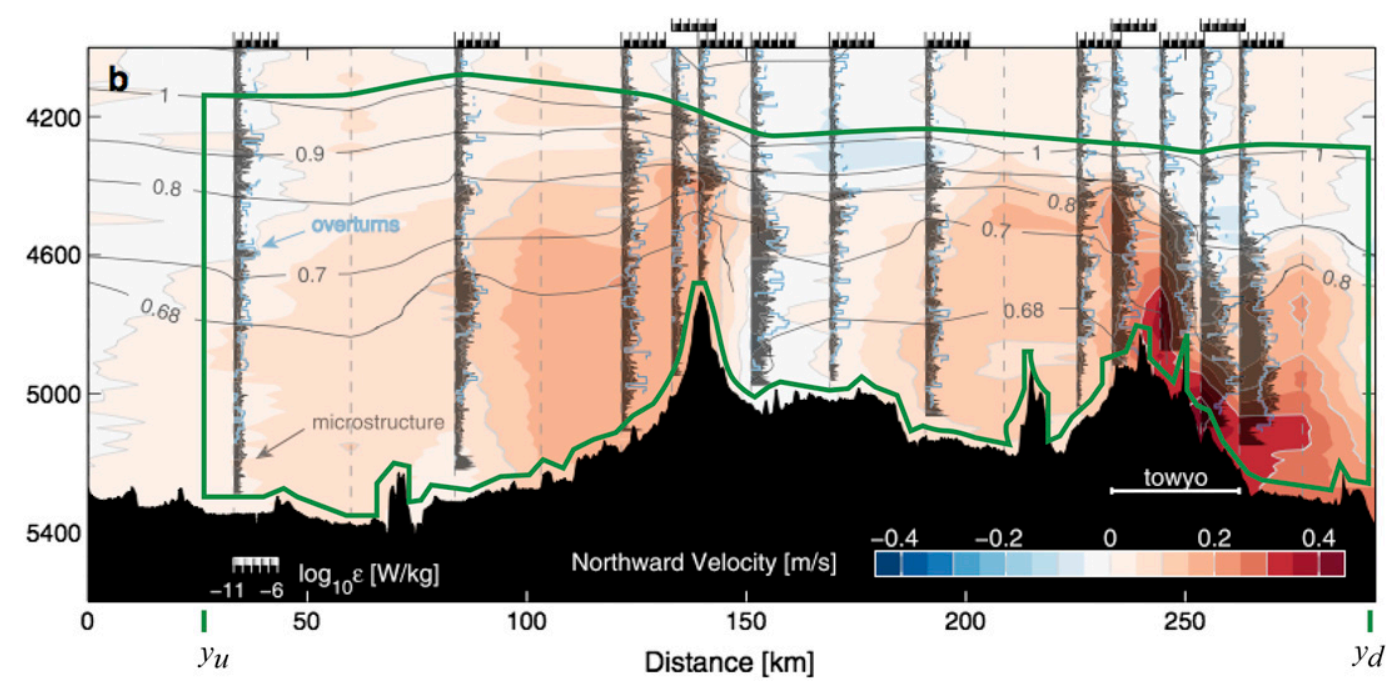

FIG. 6. The control area $A$ outlined in green is the $2 \mathrm{D}$ control area used to calculate the change in Bernoulli function. The figure also shows the rate $\varepsilon$ of turbulent kinetic energy dissipation (stick profiles), velocity (color), and potential temperature (contours), all from Fig. 2b of Alford et al. 2013.

model of interior abyssal circulation. However, this analogy is imperfect since the island rule prediction of $Q_{s}$ includes the transport in any western boundary layer on the east coast of the island: a contribution not contemplated within the Stommel-Arons framework. In any case, the island rule predicts southward flow if the dissipation and bottom drag within the Samoan Passage are not accounted for: one of the central conclusions of this work.

\section{c. Dissipation in the Samoan Passage}

Alford et al. (2013) report measurements of velocity and turbulent kinetic energy dissipation rate $\varepsilon$ along the central axis of the main channel of the Samoan Passage (Fig. 6). The topography is complex and there are several deep-water routes, but the main channel lies on the eastern side of the passage. Here there are two major sills, and elevated values of $\varepsilon$ and velocity can be seen in their vicinity. Thorpe et al. (2018) argue that the rebound in the isopycnals in the lee of the northern (downstream) sill is a hydraulic jump. This and the region of elevated $\varepsilon$ around the other sill occur over stretches of $40-60 \mathrm{~km}$, whereas shallow water theory would represent jumps as discontinuities in the velocity and layer thickness. For this reason, we will choose the beginning ( $s=0$ in Fig. 2 ) of the integration contour $C$ to coincide with the upstream end ( $y=y_{u}$ in Fig. 6) and the contour end $\left(s=s_{C}\right)$ to coincide with the downstream end $y=y_{d}$. With these choices, $C$ now begins near the upstream end of the Samoan Passage and terminates at the downstream end. In this case, $\delta B$ in (6) should be interpreted as the total drop in Bernoulli function
$B$ from $y=y_{u}$ to $y=y_{d}$, and the bottom drag term (final term in numerator) is to be calculated only over $C$ itself and not in the gap.

To estimate the drop $\delta B$ from $y_{u}$ to $y_{d}$, we consider a 2D control area $A$ (outlined in green in Fig. 6) that includes the region over which $\varepsilon$ is measured. We make several strong assumptions: first, that the flow within is 2D and second, that the measured values are representative of 15 -month mean values. We also assume that there is only weak motion at the top of the area, which coincides with the $1^{\circ} \mathrm{C}$ potential temperature contour, and this is largely confirmed by velocity measurements. Both assumptions can be challenged, but we are restricted by the data that exists.

The ability to rigorously estimate the uncertainty in this dissipation average is severely limited by available microstructure data, but there are two lines of reasoning to suggest that it may be no larger than the relative uncertainty in the transport average (i.e., $20 \%$ or so, corresponding to a 1-Sv standard deviation on the lowpassed transports with an average of $5.4 \mathrm{~Sv}$ ). First, the section shown in Fig. 6 was occupied over several days, with the microstructure profiles occurring at random tidal phases, thereby effectively averaging out tidal variability to a good degree. Second, our analysis of density overturns in moored profiler time series near several of the sills have shown little direct correlation between transport and dissipation. Dissipation is intermittent but averages are fairly stable. This work is being prepared for a future publication, but it does imply that a dissipation uncertainty estimate based on transport variability would not provide much benefit. 
As argued in appendix B, the drop in Bernoulli function in the present setting is due primarily to the energy dissipation occurring within the control area $A$ and to the work done by turbulent stresses acting along the lower boundary of $A$. If $A$ extends right to the bottom, the work term goes to zero and $\delta B$ is entirely due to dissipation within $A$. (The no-slip boundary condition implies that work due to bottom friction is zero.) Since the measurements of $\varepsilon$ by Alford et al. (2013) only go to within $50 \mathrm{~m}$ or so of the bottom, we need to estimate the dissipation below that level. We therefore distinguish the dissipation in the observed area $A$ from that in the underlying region $A^{-}$:

$$
\delta B=\frac{\iint_{A} \rho \varepsilon d A+\iint_{A^{-}} \rho \varepsilon d A}{M},
$$

where $M$ is the depth integrated average mass flux per unit width in the $y$ direction. The second integral in (7) is approximately equal to the work done by shear stresses acting along the boundary between $A$ and $A^{-}$and can be estimated, as described in appendix $\mathrm{B}$, from the quadratic drag coefficient.

\section{d. Frictional drag around the west side of Manihiki}

The Samoan Passage spans only a small part of the total latitude range of the Manihiki Plateau and therefore the integration contour $C$ has a significant length along the western side of the plateau north and south of the passage (Fig. 7). Estimation of the bottom drag along these portions of $C$ is difficult because velocity observations exist only within the Samoan Passage. To establish an estimate of how significant these drag terms could be, we turn to results from a numerical model. The model has 90 vertical levels and a horizontal resolution of $1 / 48^{\circ}$ and computes forward solutions of the Massachusetts Institute of Technology general circulation model (MITgcm; Marshall et al. 1997). This high-resolution simulation is based on the coarser data-assimilating Estimating the Circulation and Climate of the Ocean, Phase II (ECCO2; Menemenlis et al. 2008) state estimate. A further description and analysis of the model may be found in Rocha et al. (2016a) and Rocha et al. (2016b).

One of the more challenging aspects of the frictional drag estimate is the selection of the route that $C$ takes along the west side of the Manihiki Plateau. In textbook examples, this part of the contour would typically lie along a vertical wall, so that no cross-contour transport would be possible. One would therefore like to choose a contour that is likely to permit the least amount of normal transport. Possibilities include streamlines, isobaths and constant $f / d$ contours. Streamlines are the best choice and are used downstream of the Samoan Passage,

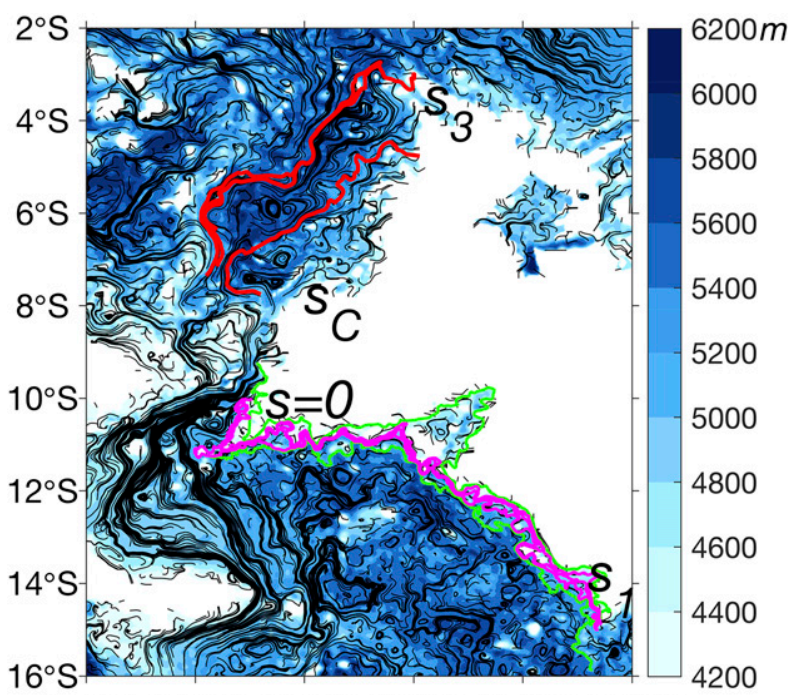

$172^{\circ} \mathrm{W} 170^{\circ} \mathrm{W} 168^{\circ} \mathrm{W} 166^{\circ} \mathrm{W} 164^{\circ} \mathrm{W} 162^{\circ} \mathrm{W}$

FIG. 7. Various choices for the integration contour $C$ to the west of the Manihiki Plateau and upstream and downstream of the Samoan Passage. Blue shading indicates bottom depth, while black contours are streamlines of near-bottom velocity from the numerical model. White areas indicate areas with model bottom temperatures warmer than $1^{\circ} \mathrm{C}$. Colors represent various choices of the integration paths, with red indicating choices that approximately follow bottom streamlines extending downstream of the Samoan Passage. Green contours follow isobaths while magenta contours follow contours of constant layer depth $d$. The locations marked $s_{1}, s_{3}$, etc. correspond to the beginnings and ends of contour segments following the plan indicated in Fig. 2.

where they are smooth and long. The upstream region is more complex and a variety of choices are used (Fig. 7) as integration contours.

\section{Estimation of the transport east of Manihiki}

If (7) is used to substitute for $\delta B$ in (6) we have

$$
Q_{S}=Q_{I}+Q_{\varepsilon}+Q_{C},
$$

where

$$
\begin{aligned}
Q_{I} & =\frac{(f / d)_{N}}{(f / d)_{N}-(f / d)_{S}} \iint_{A_{E}} w_{e} d A_{E} \cong 0-0.24 \mathrm{~Sv}, \\
Q_{\varepsilon} & =\frac{\iint_{A} \rho \varepsilon d A}{M\left[(f / d)_{N}-(f / d)_{S}\right]} \cong 0.58-1.64 \mathrm{~Sv}, \\
Q_{C} & =-\frac{\int_{0}^{s_{C}} C_{d} \frac{|\mathbf{u}|}{d} \mathbf{u} \cdot \mathbf{l} d s}{(f / d)_{N}-(f / d)_{S}} \cong 0.05-0.75 \mathrm{~Sv},
\end{aligned}
$$

and where the parameter values used to make the above estimates appear in Table 1. 
TABLE 1. Parameter values.

\begin{tabular}{llc}
\hline \hline Parameter & Description & Range of values \\
\hline$w_{e}$ & Diapycnal velocity across $1^{\circ} \mathrm{C}$ surface & 0 to $4.4 \times 10^{-5} \mathrm{~cm} \mathrm{~s}{ }^{-1}$ \\
$\iint_{A_{E}} w_{e} d A$ & Quadratic bottom drag coefficient & $0.87-0.99 \mathrm{~Sv}$ \\
$C_{d}$ & Rate of dissipation of turbulent kinetic energy & $(1.0-3.0) \times 10^{-3}$ \\
$\varepsilon$ & & See Fig. 6 for values \\
$\iint_{A} \rho \varepsilon d A$ & Mass flux per unit width of channel & $354.0 \mathrm{~kg} \mathrm{~m}^{2} \mathrm{~s}^{-3}$ \\
$M$ & Value of $f / d$ along the southern part of $C$ & $(1.05 \pm 0.25) \times 10^{6} \mathrm{~kg} \mathrm{~m}^{-1} \mathrm{~s}^{-1}$ \\
$(f / d)_{S}$ & Value of $f / d$ along the northern part of $C$ & $-8 \times 10^{-8} \mathrm{~m}^{-1} \mathrm{~s}^{-1}$ \\
$(f / d)_{N}$ & & $-(1.0-2.0) \times 10^{-8} \mathrm{~m}^{-1} \mathrm{~s}^{-1}$ \\
\hline
\end{tabular}

Here $Q_{I}$ is the contribution to the total flux from the interior diapycnal velocity $w_{e}=4.4 \times 10^{-5} \mathrm{~cm} \mathrm{~s}^{-1}$ over the open area $A_{E}$, here estimated from -0.14 to $-0.24 \mathrm{~Sv}$ depending on the integration contour. The value of $w_{e}$ is regarded as an upper bound and therefore we believe that the actual transport lies in the range from zero to $-0.24 \mathrm{~Sv}$. We have also estimated the transport error that arises from continuing the integration contour $C$ all the way to the equatorial singularity. This is done by comparing $Q_{I}$ to the value that would occur if the equator were avoided by splicing in a shortcut section, as depicted schematically in Fig. 2. Details of the calculation can be found in appendix A. For the integration contour shown in Fig. 5, which gives $Q_{I}=-0.24 \mathrm{~Sv}$, the correction due to the shortcut (dashed segment at $4^{\circ} \mathrm{S}$ ) is only $-0.0074 \mathrm{~Sv}$ and is therefore negligible. For the contour and shortcut used to obtain $Q_{I}=-0.14 \mathrm{~Sv}$, the correction is $0.02 \mathrm{~Sv}$, resulting in an adjusted transport of $-0.12 \mathrm{~Sv}$, which falls within the uncertainty range already established.

Parameter $Q_{\varepsilon}$ is the contribution from the internal kinetic energy dissipation in the Samoan Passage. We integrated the values of $\rho \varepsilon$ measured within the area $A$, and shown in Fig. 6, and added the estimate from the bottom $50 \mathrm{~m}$ of the water column (area $A^{-}$) as described in appendix B. The mass flux $M$ per unit width was estimated using the same data. The range of estimates $(0.58-1.64 \mathrm{~Sv})$ for $Q_{\varepsilon}$ largely comes from uncertainty in our estimate of $\varepsilon$ in regions where no measurements were made. Finally, $Q_{C}$ is the contribution from the bottom drag integrated around those portions of the contour $C$ that wrap around the western side of the Manihiki Plateau. We used a drag coefficient ranging from $10^{-3}$ to $3 \times 10^{-3}$ based on estimates of $C_{d}$ from direct measurements of turbulence in shallow water. Measured values span from $10^{-3}$ to $10^{-2}$ (Trowbridge and Lentz 2018) based on the strength of the waveinduced velocity. For our abyssal flow, in which the wave-induced velocity is expected to be small, we chose values at the lower end of this range.

Summing the contributions from the various constituents yields the range

$$
Q_{S}=(0.39-2.39) \mathrm{Sv},
$$

as compared with the two previously cited hydrographic estimates 2.3 Sv [from the Roemmich et al. (1996) analysis of the Taft et al. (1991) TEW data] and 2.8 Sv [from the Roemmich et al. (1996) analysis of WOCE Section P31 data]. Uncertainty estimates are difficult, but these observed values should be considered in the context of the time variability of the Samoan Passage transport. There the standard deviation of the 100-h low-pass-filtered transport is about $1 \mathrm{~Sv}$. The standard deviation due to tides in the unfiltered record is much larger, but a hydrographic estimate of the transport based on a single section should be more representative of the subtidal average. The extent to which the same level of variability is experienced east of Manihiki is unknown, but we note that the edge of the plateau potentially acts as a waveguide that could transmit variability counterclockwise from the Samoan Passage to the east side of the plateau.

The $Q_{S}$ is the total transport to the east of the Manihiki Plateau, equal to the sum of the transport $Q_{\mathrm{WLB}}$ in the western boundary layer along the east flank of the plateau and the Stommel-Arons transport $Q_{\mathrm{SA}}$ to the east of the deep western boundary current. For our layer model, the latter is given by

$$
Q_{\mathrm{SA}} \cong \int_{s_{1}+\delta_{\mathrm{WBL}}}^{s_{2}} \frac{f w_{e}}{d \frac{\partial}{\partial n}\left(\frac{f}{d}\right)} d s,
$$

where the integration is carried out along the southern part of the integration contour $C$ and $s_{1}$ and $s_{2}$ are as defined in Fig. 2. The integration begins at $s=s_{1}+\delta_{\mathrm{WBL}}$, which corresponds to the eastern edge of the deep western boundary current. For largest magnitude of $w_{e}$ used, the result of this integration yields southward transport $Q_{\text {SA }}$ of only $-0.02 \mathrm{~Sv}$, and thus

$$
Q_{\mathrm{WLB}}=Q_{S}-Q_{\mathrm{SA}}=(0.41-2.41) \mathrm{Sv},
$$

in view of (9). How the western boundary current transport is fed requires knowledge of conditions to the 
south of the Samoan Passage and Manihiki Plateau. The most widely studied section lies at $30^{\circ} \mathrm{S}$, where the northward flow is observed to be split into two deep western boundary currents, one along the Kermadec Ridge and the other along the Louisville Ridge (Whitworth et al. 1999).

\section{Relationship to mixing in the abyssal Pacific}

This study was motivated in part by observations of strong mixing within the Samoan Passage and the supposition that equally strong mixing is unlikely to occur within the flow that is diverted to the east of the Manihiki Plateau. But how important is the local mixing in this region in the overall scheme of mixing and upwelling in the abyssal Pacific? Consider a fluid parcel that enters the Samoan Passage from the south, continues into the abyssal North Pacific, and makes its way up and out of the abyss. To do so, it must mix with overlying fluid of lower density, a process that occurs through intense turbulent entrainment in the Samoan Passage and through a geographically complex distribution of mixing processes in the abyssal North Pacific, characterized holistically by an average turbulent diffusivity $\kappa \cong$ $10^{-4} \mathrm{~m}^{2} \mathrm{~s}^{-1}$ (Munk 1966). Following Bryden and Nurser (2003), the rate of mixing due to entrainment within a deep strait can be approximated by the average volume flow rate $Q$ times the average decrease in density $\delta \rho$ observed between the upstream and downstream ends of the strait. For the Samoan Passage we take the Voet et al. (2016) estimate of $Q=5.4 \mathrm{~Sv}$ as well as the estimate $\delta \rho \cong 0.04 \mathrm{~kg} \mathrm{~m}^{-3}$ based on Voet et al. (2015, their Fig. 2). We note that the latter is consistent with Freeland's (2001) estimate of $0.03-0.05 \mathrm{~kg} \mathrm{~m}^{-3}$. The product of these values is

$$
Q \delta \rho \cong 2.2 \times 10^{5} \mathrm{~kg} \mathrm{~s}^{-1} \text { (Samoan Passage) } .
$$

The equivalent estimate for mixing over the area $A_{\mathrm{AP}}$ of the abyssal North Pacific is $A_{\mathrm{AP}} \kappa(d \rho / d z)$, where $A_{\mathrm{AP}} \cong 3 \times$ $10^{7} \mathrm{~km}^{2}$ and $d \rho / d z$ ranges over $(0.4-2.5) \times 10^{-5} \mathrm{~kg} \mathrm{~m}^{-4}$ below $4000 \mathrm{~m}$ (King et al. 2012). With these values,

$$
A_{\mathrm{AP}} \kappa(d \rho / d z)=(1.2-7.5) \times 10^{4} \mathrm{~kg} \mathrm{~s}^{-1} \text { (abyssal N. Pacific). }
$$

Another way of evaluating the importance of the Samoan Passage is to consider how far northward an exiting fluid parcel must travel before it undergoes the same density decrease $\left(\delta \rho \cong 0.04 \mathrm{~kg} \mathrm{~m}^{-3}\right)$ that it experienced in the Samoan Passage. Alford et al. (2013) observe that the 26.13 neutral density surface exits the Samoan Passage at about the same level $(4500 \mathrm{~m})$ as our $1^{\circ} \mathrm{C}$ interface. A further density decrease of 0.04 units would put the parcel on the 26.09 surface, which extends northward of $50^{\circ} \mathrm{N}$ in the Pacific at a depth of about $4000 \mathrm{~m}$ (WOCE Section P15). Thus, the parcel potentially continues into the far North Pacific and gains approximately $500 \mathrm{~m}$ elevation.

Consistent with the findings of Bryden and Nurser (2003) for the deep Atlantic Ocean, the mixing in the Samoan Passage appears to be a significant factor in the overall picture. The partitioning of flow between the Samoan Passage and the Penrhyn basin then becomes a factor in the overall narrative of abyssal mixing and how the distribution of mixing might change in a warming abyss.

\section{Discussion}

It is apparent that the abyssal form of the island rule developed in this work is not a practical tool for precise predictions of transports. Unlike the traditional form for wind driven flow, which requires only wind stress measurements, the present form requires a range of problematic information, including diapycnal velocities, dissipation values, and drag coefficients. Nevertheless, the island rule formulation provides a good framework for identification and evaluation of the factors that set the transport to the east of the island. Our formulation identifies turbulent dissipation in the Samoan Passage and to a lesser extent frictional bottom drag on the western side of the Manihiki Plateau as the main ingredients. Without them, the predicted transport to the east of Manihiki would be southward. The predicted transport range of $0.39-2.39 \mathrm{~Sv}$ compares with the observed values of 2.3-2.8 Sv (Roemmich et al. 1996), both based on single hydrographic sections and both subject to uncertainty as time means. [The direct measurements of the Samoan Passage transport by Rudnick (1997) and Voet et al. (2016) vary in time from 1-2 to over $10 \mathrm{~Sv}$, and the transport east of Manihiki may undergo relative fluctuations of similar size.]

Our analytical model also presents some elements that are novel from the perspective of geophysical fluid dynamics. One involves the singularity that occurs where the equator intersects with the grounding contour of the layer interface (the $1^{\circ} \mathrm{C}$ isotherm). This location acts as an accumulation point for $f / d$ contours and therefore exerts a major influence over the shape of the open segments of the integration circuit. The singular nature of this point can probably be resolved through consideration of ageostrophic influences near the equator. In the unapproximated form of the circulation integral, the integration contours ought to lie along an isoline of potential vorticity $(f+\zeta) / d$, approximated $f / d$ in our model. As the equator is approached, $f$ vanishes and the detailed shape of the contour becomes strongly 
influenced by the relative vorticity $\zeta$. A tacit assumption in our calculations is that the region over which relative vorticity is important is too small to have much effect on the total value of the integrals. In addition, the proximity of the integration circuits to the equator means that the predicted transport $Q_{S}$ might contain zonal flow running along the equator. However, since the layer depth $d$ becomes small in the vicinity of the accumulation point, the actual contribution to $Q_{S}$ is arguably small as well. A third aspect that is worth exploring is the extent to which the model applies in the presence of time dependence. It is possible to generalize the formulation by including time derivatives [see Eq. (2)], but the integration contour $C$ must then be allowed to change with time. Of course, the shallow-water model has its own set of limitations, none the least of which is the lack of interaction with the overlying fluid. Future plans call for further exploration of all of these issues within the context of numerical simulations.

In addition to implications for mixing, the partitioning of flow between the Samoan Passage and the route east of Manihiki raises some intriguing questions about dynamics. One concerns the presence of hydraulic control in the Samoan Passage, but most likely not to the east of Manihiki: how is this possible? Normally, hydraulic control implies an influence over the flow far upstream. In standard rotating hydraulic models (e.g., Whitehead et al. 1974; Gill 1977; Pratt and Whitehead 2008) the upstream influence is exerted by an edge wave that is excited at the controlling sill any time there is a temporal change in the approach flow (Pratt and Chechelnitsky 1997). With vertical walls, the edge wave is a Kelvin wave; when the layer depth vanishes, the edge wave becomes a frontal wave (Stern 1980). In either case an upstream-propagating, Southern Hemisphere edge wave excited at one of the sills in the Samoan Passage would not propagate far upstream but would instead attempt to circle the Manihiki Plateau in a counterclockwise direction and possibly reenter the passage from the north. The chain of events that occurs is perhaps best simulated in a model, but the overall implication is that the upstream influence of the sills in the Samoan Passage primarily involves control over the partitioning of the flow.
Although the hydraulics and upstream influence may act in novel ways, these processes do not explicitly factor into our particular island rule formulation. Hydraulic control leads to spilling, supercritical flows that tend to experience shear instabilities, jumps, and high dissipation regimes, so there is an implicit connection with the dissipation term $\delta B$ in the island rule. A different approach may be required to make the connection with hydraulic control explicit.

Acknowledgments. This work was supported by the National Science Foundation under Grants OCE-1029268, OCE-1029483, OCE-1657264, OCE-1657870, OCE-1658027, and OCE-1657795. We thank the captain, crew, and engineers at APL/UW for their hard work and skill.

\section{APPENDIX A}

\section{$Q_{S}$ Estimate Using Modified Northern Contour}

Suppose that integration contour extending from $s=$ $s_{1}$ to $s=s_{3}$ in Fig. 2 is altered by excising the segments that approach the equator and replacing them with a shortcut consisting of a zonal segment extending from $s=s_{2}^{-}$and $s=s_{2}^{+}$as shown in the inset. The latter is situated sufficiently far from the equator that relative vorticity can be ignored in comparison to the local value $f=f_{o}$ there. Then (4) is replaced by

$$
\begin{aligned}
& q_{S} \int_{s_{1}}^{s_{2}^{-}} d \mathbf{u} \cdot \mathbf{n} d s+\int_{s_{2}^{-}}^{s_{2}^{+}} f_{o} \mathbf{u} \cdot \mathbf{n} d s+q_{S} \int_{s_{2}^{+}}^{s_{3}} d \mathbf{u} \cdot \mathbf{n} d s \\
& \quad=-\left(\frac{f}{d}\right)_{S} Q_{S}+f_{o} \int_{s_{2}^{-}}^{s_{2}^{+}} \mathbf{u} \cdot \mathbf{n} d s+\left(\frac{f}{d}\right)_{N}\left(Q_{N}-Q_{o}\right),
\end{aligned}
$$

where now $Q_{S}$ represents the volume flux across the southern segment $\left(s=s_{1}\right.$ to $\left.s=s_{2}{ }^{\prime}\right), Q_{N}$ represents the volume flux across the entire northern segment $(s=$ $s_{2}^{-}$to $\left.s=s_{3}\right)$, and $Q_{o}$ is the northward flux across the shortcut $\left(s=s_{2}^{-}\right.$to $\left.s=s_{2}^{+}\right)$. Over the path of the shortcut, let $d=D+\Delta d(s)$, where $D$ is the depth at $s=s_{2}^{+}$. As an approximation, we divide the integral into $J$ segments of equal arc length $\Delta s_{j}$, and assume constant layer thickness $D+\Delta d_{j}$ within each segment. Thus,

$$
\begin{aligned}
f_{o} \int_{s_{2}^{-}}^{s_{2}^{+}} \mathbf{u} \cdot \mathbf{n} d s & \cong f_{o} \sum_{j=1}^{J} \frac{\Delta s_{j} v_{j} d_{j}}{d_{j}}=f_{o} \sum_{j=1}^{J} \frac{\Delta Q_{j}}{D+\Delta d_{j}}=f_{o} \sum_{j=1}^{N} \frac{\Delta Q_{j}}{D\left(1+\Delta d_{j} / D\right)} \\
& \cong f_{o} \sum_{j=1}^{J} \frac{\Delta Q_{j}\left(1-\Delta d_{j} / D\right)}{D}=\frac{f_{o}}{D}\left[\sum_{j=1}^{J} \Delta Q_{j}-\sum_{j=1}^{J} \Delta Q_{j} \frac{\Delta d_{j}}{D}\right]=\left(\frac{f}{d}\right)_{N}\left[Q_{o}-\sum_{j=1}^{J} \Delta Q_{j} \frac{\Delta d_{j}}{D}\right]
\end{aligned}
$$


so that (A1) now becomes

$$
\begin{aligned}
& q_{S} \int_{s_{1}}^{s_{2}^{-}} d \mathbf{u} \cdot \mathbf{n} d s+q_{S} \int_{s_{2}^{+}}^{s_{3}} d \mathbf{u} \cdot \mathbf{n} d s+\int_{s_{2}^{+}}^{s_{3}} f_{O} \mathbf{u} \cdot \mathbf{n} \\
& \quad=\left(\frac{f}{d}\right)_{N} Q_{N}-\left(\frac{f}{d}\right)_{S} Q_{S}-\left(\frac{f}{d}\right)_{N} \sum_{j=1}^{J} \Delta Q_{j} \frac{\Delta d_{j}}{D} .
\end{aligned}
$$

This expression is the same as (2) except for the presence of the final term representing the contribution to the shortcut. Substitution into (2) results in the modified island rule:

$$
Q_{S}=\frac{(f / d)_{N} \iint_{A_{E}} w_{e} d A_{E}+\delta B-\int_{0}^{s_{C}} C_{d} \frac{|\mathbf{u}|}{d} \mathbf{u} \cdot \mathbf{l} d s+(f / D)_{N} \sum_{j=1}^{J} \Delta Q_{j} \frac{\delta d_{j}}{D}}{\left[(f / d)_{N}-(f / d)_{S}\right]}
$$

The final term in the numerator can be estimated by applying the Stommel-Arons formula (10) to calculate each $\Delta Q_{j}$. We have carried out this calculation using a shortcut lying at $4^{\circ} \mathrm{S}$ (dashed line in Fig. 5), resulting in a value $\sum_{j=1}^{J} \Delta Q_{j} \delta d_{j} / D$ of $-0.0074 \mathrm{~Sv}$. The value of $\iint_{A_{E}} w_{e} d A_{E}$, previously $0.87 \mathrm{~Sv}$, is reduced to $0.72 \mathrm{~Sv}$. due to the decrease in the area $A_{E}$. These two factors result in net increase in the estimate of $Q_{S}$ by a $0.04 \mathrm{~Sv}$. We had previously estimated the contribution from the upwelling term to be from 0 to $-0.24 \mathrm{~Sv}$, so the revised transport is already within this range.

\section{APPENDIX B}

\section{Estimation of $\delta B$}

In the homogeneous and hydrostatic setting of shallow-water dynamics, the Bernoulli function is independent of $z$. We then associate its value at any horizontal location with the depth-average value of the stratified layer that is being sampled. In order to motivate our estimate of the drop in this average value from $y=y_{u}$ and $y=y_{d}$, it is helpful to consider the mechanical energy equation for steady, incompressible flow. A useful form of this equation is

$$
\frac{\partial}{\partial x_{j}}\left(\rho u_{j} B\right)=\frac{\partial}{\partial x_{j}}\left(2 \mu u_{i} e_{i j}\right)-\rho \varepsilon,
$$

where $e_{i j}=(1 / 2)\left(\partial u_{i} / \partial x_{j}+\partial u_{j} / \partial x_{i}\right), B=|\mathbf{u}|^{2} / 2+p / \rho+g z$, and $\mu$ is the dynamic viscosity.

We integrate (B1) over the control area $A$ (Fig. 6) and disregard the advection of $B$ across the top boundary (where the flow is assumed to be quiescent) and across the bottom boundary (which could be chosen as a streamline close to the bottom). Then the net drop in the flux of $B$ between the end boundaries is

$$
\begin{aligned}
& \int_{h\left(y_{u}\right)+\delta_{b}}^{h\left(y_{u}\right)+d\left(y_{u}\right)+\delta_{b}}(\rho v B) d z-\int_{h\left(y_{d}\right)+\delta_{b}}^{h\left(y_{d}\right)+d\left(y_{d}\right)+\delta_{b}}(\rho v B) d z \\
& \quad=W_{f}+\iint_{A} \rho \varepsilon d A,
\end{aligned}
$$

where $\delta_{b}$ is the height above the bottom over which measurements of $\varepsilon$ are lacking and $W_{f}=\oint_{\partial \mathrm{A}} 2 \mu u_{i} e_{i j} n_{j} d s$ is the rate of work done by viscous stresses acting around the boundary $\partial A$ of $A$, the unit normal to which is $n_{j}$. The largest contribution to this term is expected to arise from viscous stresses acting along the bottom portion of $A$. In a turbulent flow the analogous stress would be provided by turbulent momentum fluxes (terms like $\rho \overline{v^{\prime} w^{\prime}}$ ) in the presence of a mean velocity $V$, giving rise to rate of work proportional to $\rho v^{\prime} w^{\prime} V$. The latter would act along the bottom of $A$ and could be interpreted as the rate of work done by drag. This term would be zero if $A$ extended right to the bottom (where the velocity is zero). In fact, Alford et al. (2013) only measured $\varepsilon$ to within about $50 \mathrm{~m}$ of the bottom, so we must choose the bottom of $A$ to lie somewhat shallower than the physical bottom. In this case both terms on the right hand side of (B2) are in play and we will estimate the drag term using a quadratic drag parameterization (i.e., $v^{\prime} w^{\prime}=C_{d} v_{b}^{2}$, where $v_{b}$ is the $y$-velocity component at the bottom of $A$ ).

In the above formulation $\rho, B$, etc. depend on $z$, whereas each of these quantities is $z$ independent in the lower layer of the shallow-water model that forms the basis for our island rule formulation. We associate the term $\delta B$ that arises in (6) with a drop in the depthaverage $B$ in the more general, $z$-dependent situation. The left-hand side of (B2) can be approximated as

$$
\int_{h\left(y_{u}\right)}^{h\left(y_{u}\right)+d\left(y_{u}\right)}(\rho v B) d z-\int_{h\left(y_{d}\right)}^{h\left(y_{d}\right)+d\left(y_{d}\right)}(\rho v B) d z \cong M(\delta B),
$$

where $\delta B$ is the drop in the depth-average value of $B$ between $y_{u}$ and $y_{d}$, and 


$$
M=\int_{h(y)+\delta_{b}(y)}^{h(y)+d(y)} \rho v d z \cong \int_{h(y)}^{h(y)+d(y)} \rho v d z
$$

is the horizontal mass flux per unit width over the depth of $A$. [Although $M$ would be conserved in a 2D setting, it depends weakly on $y$ along the actual section of observations (Fig. 6) and we therefore take $M$ to be the average value between $y_{u}$ and $y_{d}$.] Use of these approximations in (B2) yields

$$
\begin{aligned}
\delta B= & M^{-1} \iint_{A} \rho \varepsilon d A+W_{f} / M=\iint_{A} \rho \varepsilon d A / M \\
& +C_{d} \int_{y_{u}}^{y_{d}} \frac{v_{b}^{2}}{d} d y,
\end{aligned}
$$

now using the quadratic drag formula to estimate $W_{f} / M$. The velocity $v_{b}$ is that measured approximately $50 \mathrm{~m}$ above the bottom. (Note that the velocities measured from $50 \mathrm{~m}$ to several hundred meters above the bottom are remarkably constant with $z$, as indicated in Fig. 6.)

The above approach ignores the effects of advection of $B$ across the bottom boundary of the area $A$, an assumption that is justified if this boundary coincides with streamlines of the flow, or nearly so. This assumption could break down where abrupt horizontal changes and strong vertical motion occur in the vicinity of the bottom. Dissipation in these hot spots is unaccounted for in our formulation.

\section{REFERENCES}

Alford, M., J. B. Girton, G. Voet, G. S. Carter, J. B. Mickett, and J. M. Klymak, 2013: Turbulent mixing and hydraulic control of abyssal water in the Samoan Passage. Geophys. Res. Lett., 40, 4668-4674, https://doi.org/10.1002/grl.50684.

Bryden, H. L., and A. J. G. Nurser, 2003: Effects of strait mixing on ocean stratification. J. Phys. Oceanogr., 33, 1870-1872, https:// doi.org/10.1175/1520-0485(2003)033<1870:EOSMOO > 2.0.CO;2.

Dale, A. C., and J. A. Barth, 2001: The hydraulics of an evolving upwelling jet flowing around a cape. J. Phys. Oceanogr., 31, 226-243, https://doi.org/10.1175/1520-0485(2001)031<0226: THOAEU $>2.0 . \mathrm{CO} ; 2$.

Ferrari, R., A. Mashayek, T. McDougall, M. Nikurashin, and J.-M. Campin, 2016: Turning the ocean mixing upside down. J. Phys. Oceanogr., 46, 2239-2261, https://doi.org/10.1175/JPO-D15-0244.1.

Freeland, H., 2001: Observations of the flow of abyssal water through the Samoa Passage. J. Phys. Oceanogr., 31, 2273-2279, https://doi.org/10.1175/1520-0485(2001)031<2273:OOTFOA $>$ 2.0.CO;2.

Gill, A. E., 1977: The hydraulics of rotating-channel flow. J. Fluid Mech., 80, 641-671, https://doi.org/10.1017/S0022112077002407.

Godfrey, J. S., 1989: A Sverdrup model of the depth-integrated flow from the world ocean allowing for island circulations. Geophys. Astrophys. Fluid Dyn., 45, 89-112, https://doi.org/ 10.1080/03091928908208894.
King, B., M. Stone, H. P. Zhang, T. Gerkema, M. Marder, R. B. Scott, and H. L. Swinney, 2012: Buoyancy frequency profiles and internal semidiurnal tide turning depths in the oceans. J. Geophys. Res., 117, C04008, https://doi.org/10.1029/ 2011JC007681.

Kunze, E., E. Firing, J. M. Hummon, T. K. Chereskin, and A. M. Thurnherr, 2006: Global abyssal mixing inferred from lowered ADCP shear and CTD strain profiles. J. Phys. Oceanogr., 36, 1553-1576, https://doi.org/10.1175/JPO2926.1.

Marshall, J., A. Adcroft, C. Hill, L. Perelman, and C. Heisey, 1997: A finite-volume, incompressible Navier Stokes model for studies of the ocean on parallel computers. J. Geophys. Res., 102, 5753-5766, https://doi.org/10.1029/96JC02775.

Menemenlis, D., J.-M. Campin, P. Heimbach, C. Hill, T. Lee, A. Nguyen, M. Schodlok, and H. Zhang, 2008: ECCO2: High resolution global ocean and sea ice data synthesis. Mercator Ocean Quarterly Newsletter, No. 31, Mercator Ocean International, Ramonville Saint-Agne, France, 13-21, https:/www.mercatorocean.fr/wp-content/uploads/2015/06/lettre_31_en.pdf.

Munk, W. H., 1966: Abyssal recipes. Deep-Sea Res. Oceanogr. Abstr., 13, 707-730, https://doi.org/10.1016/0011-7471(66) 90602-4.

Musgrave, R. C., J. MacKinnon, R. Pinkel, A. Waterhouse, and J. Nash, 2016: Tidally driven processes leading to nearfield turbulence in a channel at the crest of the Mendocino Escarpment. J. Phys. Oceanogr., 46, 1137-1155, https://doi.org/ 10.1175/JPO-D-15-0021.1.

Pedlosky, J., 1987: An inertial theory of the equatorial undercurrent. J. Phys. Oceanogr., 17, 1978-1985, https://doi.org/10.1175/ 1520-0485(1987)017<1978:AITOTE > 2.0.CO;2.

_ L. J. Pratt, M. A. Spall, and K. R. Helfrich, 1997: Circulation around islands and ridges. J. Mar. Res., 55, 1199-1251, https:// doi.org/10.1357/0022240973224085.

—, R. Iacono, E. Napolitano, and M. A. Spall, 2011: The twolayer skirted island. J. Mar. Res., 69, 347-382, https://doi.org/ 10.1357/002224011798765222.

Pratt, L. J., and M. Chechelnitsky, 1997: Principles for capturing the upstream effects of deep sills in low resolution ocean models. Dyn. Atmos. Oceans, 26, 1-25, https://doi.org/10.1016/ S0377-0265(96)00483-6.

, and J. Pedlosky, 1998: Barotropic circulation around islands with friction. J. Phys. Oceanogr., 28, 2148-2162, https:// doi.org/10.1175/1520-0485(1998)028<2148:BCAIWF> 2.0.CO;2.

—_, and J. Whitehead, 2008: Rotating Hydraulics. Springer, $589 \mathrm{pp}$.

Reid, J. L., and R. J. Lynn, 1971: On the influence of the NorwegianGreenland and Weddell Seas upon the bottom waters of the Indian and Pacific Oceans. Deep-Sea Res. Oceanogr. Abstr., 18, 1063-1088, https://doi.org/10.1016/0011-7471(71)90094-5.

_ Samoan Passage. J. Phys. Oceanogr., 4, 58-73, https://doi.org/ 10.1175/1520-0485(1974)004<0058:OTFOWT>2.0.CO;2.

Rocha, C. B., S. T. Gille, T. K. Chereskin, and D. Menemenlis, 2016a: Seasonality of submesoscale dynamics in the Kuroshio Extension. Geophys. Res. Lett., 43, 11304-11311, https:// doi.org/10.1002/2016GL071349.

, T. K. Chereskin, and S. T. Gille, 2016b: Mesoscale to submesoscale wavenumber spectra in Drake Passage. J. Phys. Oceanogr., 46, 601-620, https://doi.org/10.1175/JPO-D15-0087.1.

Roemmich, D., S. Hautala, and D. Rudnick, 1996: Northward abyssal transport through the Samoan Passage and adjacent 
regions. J. Geophys. Res., 101, 14 039-14 055, https://doi.org/ 10.1029/96JC00797.

Rudnick, D. L., 1997: Direct velocity measurements in the Samoan Passage. J. Geophys. Res., 102, 3293-3302, https://doi.org/ 10.1029/96JC03286.

Stern, M. E., 1980: Geostrophic fronts, bores, breaking and blocking waves. J. Fluid Mech., 99, 687-703, https://doi.org/ 10.1017/S0022112080000833.

Stommel, H. M., and A. B. Arons, 1960: On the abyssal circulation of the world ocean (I). Stationary planetary flow patterns on a sphere. Deep-Sea Res., 6, 140-154, https://doi.org/10.1016/ 0146-6313(59)90065-6.

Taft, B. A., S. P. Hayes, G. E. Freiderich, and L. A. Codispoti, 1991: Flow of abyssal water into the Samoa Passage. Deep Sea Res., 38A (Suppl. 1), S103-S128, https://doi.org/10.1016/ S0198-0149(12)80007-0.

Talley, L. D., 2007: Pacific Ocean. Vol. 2, Hydrographic Atlas of the World Ocean Circulation Experiment (WOCE), M. Sparrow, P. Chapman, and J. Gould, Eds., International WOCE Project Office, https://doi.org/10.21976/C6WC77.

Thorpe, S. A., 2010: Turbulent hydraulic jumps in a stratified shear flow. J. Fluid Mech., 654, 305-350, https://doi.org/10.1017/ S0022112010000625.

, and L. Li, 2014: Turbulent hydraulic jumps in a stratified shear flow. Part 2. J. Fluid Mech., 758, 94-120, https://doi.org/ 10.1017/jfm.2014.502.
, J. Malarkey, G. Voet, M. H. Alford, J. B. Girton, and G. S. Carter, 2018: Application of a model of internal hydraulic jumps. J. Fluid Mech., 834, 125-148, https://doi.org/10.1017/ jfm.2017.646.

Trowbridge, J. H., and S. J. Lentz, 2018: The bottom boundary layer. Ann. Rev. Mar. Sci., 10,397-420, https://doi.org/10.1146/ annurev-marine-121916-063351.

Voet, G., J. B. Girton, M. H. Alford, G. S. Carter, J. M. Klymak, and J. B. Mickett, 2015: Pathways, volume transport and mixing of abyssal water in the Samoan Passage. J. Phys. Oceanogr., 45, 562-588, https://doi.org/10.1175/JPO-D14-0096.1.

—, M. H. Alford, J. B. Girton, G. S. Carter, J. B. Mickett, and J. M. Klymak, 2016: Warming and weakening of the abyssal flow through Samoan Passage. J. Phys. Oceanogr., 46, 2389-2401, https://doi.org/10.1175/JPO-D-16-0063.1.

Whitehead, J. A., 2005: The effect of potential vorticity on flow through a gap. J. Geophys. Res., 110, C07007, https://doi.org/ 10.1029/2004JC002720.

— A. Leetmaa, and R. A. Knox, 1974: Rotating hydraulics of strait and sill flows. Geophys. Fluid Dyn., 6, 101-125, https:// doi.org/10.1080/03091927409365790.

Whitworth, T., III, B. Warren, W. Nowlin Jr., S. Rutz, R. Pillsbury, and M. Moore, 1999: On the deep western-boundary current in the Southwest Pacific Basin. Prog. Oceanogr., 43, 1-54, https://doi.org/10.1016/S0079-6611(99)00005-1. 